\title{
PENTINGNYA MODUL KESEHATAN REPRODUKSI REMAJA BERBASIS MASALAH (KRRBM) UNTUK MELATIH DAN MENINGKATKAN KETERAMPILAN HIDUP (LIFE SKILLS) DAN SIKAP REPRODUKSI SEHAT SISWA SMP
}

\author{
Desak Made Citrawathi ${ }^{1}$, I Nengah Sumardika ${ }^{2}$, I Made Pasek Anton Santiasa ${ }^{3}$ \\ 1,2,3 Jurusan Pendidikan Biologi, Fakultas Matematika dan IImu Pengetahuan \\ Alam Universitas Pendidikan Ganesha, \\ Singrajara Indonesia
}

\begin{abstract}
Abstrak
Tujuan utama penelitian ini adalah untuk mengetahui pentingnya mengembangkan Modul Kesehatan Reproduksi Remaja Berbasis Masalah (KRRBM) untuk melatih dan meningkatkan keterampilan hidup (life skills) dalam bidang kesehatan reproduksi dan meningkatkan sikap reproduksi sehat siswa SMP. Untuk mencapai target tersebut dilakukan penelitian pengembangan yang mengacu pada model Dick dan Carey. Prosedur penelitian meliputi lima tahap, yaitu: (1) penetapan mata pelajaran, (2) analisis kebutuhan, (3) pengembangan modul KRRBM, (4) penyusunan modul, dan (5) review dan uji coba modul KRRBM. Penelitian tahap pertama ini dilakukan analisis kebutuhan dan penyusunan prototipe modul KRRBM. Penelitian dilakukan di SMP Negeri dan Swasta di Kota Singaraja-Bali. Sekolah yang dilibatkan sebagai sampel ditentukan dengan teknik purposive random sampling. Metode pengumpulan data dilakukan dengan wawancara, angket, dan FGD, dengan melibatkan kepala sekolah, guru, dan siswa. Data yang diperoleh dianalisis secara deskriptif. Hasil yang diperoleh bahwa sebagian materi KRR sudah diberikan pada mata pelajaran IPA. Informasi KRR juga diberikan pada kegiatan ekstrakurikuler Kelompok Siswa Peduli AIDS dan Narkoba, serta melalui ceramah dan poster. Strategi pembelajaran yang digunakan belum melatih keterampilan hidup terkait KRR dan belum membelajarkan sikap reproduksi sehat. Kendala yang dihadapi sekolah dalam PKRR adalah menentukan strategi pembelajaran yang sesuai untuk melatih keterampilan hidup dan pembelajaran sikap, buku sumber, waktu, dan biaya. Sekolah sangat setuju dikembangkan dan disusunnya modul KRRBM untuk membelajarkan siswa tentang KRR.
\end{abstract}

Kata kunci: Modul Berbasis Masalah, keterampilan hidup, sikap reproduksi sehat

\begin{abstract}
The main aim of this research was to study the importance for developing a Problem Base Module of Teenager's Sexual Health (KRRBM) to train and improve life skills on sexual health and develop healthy sexual attitude on primary high school students. To achieve the aim, a research and development project had been done referring to Dick and Carey model. The research procedure including five steps, those are: (1) determining the subject, (2) need analysis, (3) arranging the module, (4) constructing the module, (5) reviewing and trying the module. Need analysis had been done during the first year, and arranging prototype of the
\end{abstract}


KRRBM module. This research was conducted in several state and private primary high schools in Singaraja - Bali. The schools involved were determined through purposive random sample technique. Data collection method carried through interview, questionnaires, and FGD, involving the headmasters, teachers, and students. The result shows that some teenager's sexual health $(K R R)$ topics have been given through natural science subjects. $K R R$ has also been given through extracurricular activity of KS-PAN (students union for AIDS/HIV and narcotics awareness), pricing, and placing posters on the school wall. Learning strategy applied in the schools has not trained $K R R$ related life skills, and sexual health attitude has not been examined. Obstacles that are faced by the schools while implementing PKRR program are suitable learning strategy, learning resources, timetable, and fund. Schools are supportive to the development of KRRBM Module for teaching and training students on KRR topics.

Keywords: Problem Base Module, life skills, healthy sexual attitude

\section{PENDAHULUAN}

Remaja dekade tahun 2000-an ini sangat berbeda dengan remaja generasi sebelumnya. Masalah yang dihadapi remaja dewasa ini lebih kompleks dan sangat mengkhawatirkan dibandingkan generasi-generasi sebelumnya. Meningkatnya kemudahan aksesibilitas di era globalisasi menyediakan informasi yang sangat kaya bagi siapa saja termasuk para remaja. Arus informasi melalui media masa baik berupa media cetak seperti majalah, surat kabar, tabloid maupun media elektronik seperti radio, televisi, Hp. dan komputer, mempercepat terjadinya perubahan. Meskipun arus informasi ini menunjang berbagai sektor pembangunan, namun arus informasi ini juga dapat melemahkan sistem sosialbudaya dan ekonomi masyarakat Indonesia, dan juga memberi pengaruh negatif bagi kehidupan, termasuk kehidupan remaja. Arus informasi telah mengubah (meliberalisasi) cara berpikir, cara bersikap, dan cara bertindak para remaja berkaitan dengan seksualitas. Remaja saat ini mempunyai sifat yang permisif berkaitan dengan seksualitas sebelum menikah, sehingga menimbulkan berbagai masalah reproduksi dan seksualitas pada remaja (Duarsa, 2009). Masalah reproduksi dan seksualitas yang dihadapi remaja saat ini adalah meningkatnya jumlah remaja dengan HIV/AIDS, infeksi menular seksual (IMS), kehamilan yang tidak diinginkan (KTD), dan penyalahgunaan NAPZA (narkotika, alkohol, psikotropika, dan zat aditif). Masalah seksualitas, HIV/AIDS dan NAPZA disebut dengan istilah risiko TRIAD Kesehatan Reproduksi Remaja atau TRIAD KRR (Muadz, dkk., 2008).

Di samping karena dampak negatif dari kemajuan teknologi informasi, risiko TRIAD KRR pada remaja juga disebabkan oleh minimnya pengetahuan remaja terkait seksualitas dan reproduksi (Muzzayanah, 2008; Noviasari, dkk.,2008; Catio, 2009; Prameswara, 2009, dan Zahra, 2010). Sebagai remaja, secara fisiologis dan psikis mereka merasakan adanya dorongan seksual, dan remaja ingin mengetahui tentang seksualitas dan reproduksi. Informasi tentang seksualitas dan reproduksi umumnya 
mereka dapatkan dengan membaca buku dan melihat gambar porno yang bisa diperoleh melalui internet, serta dari teman sebaya, atau penjelasan orang tua yang tidak lengkap (Dianawati, 2003). Karena ketidaktahuan dan ketidaksiapan remaja terkait reproduksi dan seksualitas, maka remaja dapat mengalami masalah kesehatan reproduksi, termasuk masalah TRIAD, yang sangat merugikan remaja, keluarga, masyarakat, dan negara. Menurut survey Komnas Perlindungan Anak di 33 Provinsi dari Januari s.d Juni 2008 menyimpulkan bahwa: (1) 97 persen anak SMP dan SMA pernah menonton film porno; (2) 93 persen remaja SMP dan SMA pernah ciuman, genital stimulation, dan oral sex; dan (3) 62,7 persen remaja SMP tidak perawan lagi (Muadz, dkk., 2008). Data yang diberikan oleh Kisara (2008), menunjukkan bahwa sekitar 15 juta remaja usia 15-19 tahun melahirkan setiap tahunnya. Data Riskesdas (2010) menunjukkan bahwa proporsi penduduk usia 10 - 15 tahun yang pernah melakukan hubungan seksual pranikah di kalangan remaja laki-laki adalah 17,7 persen, dan pada remaja perempuan 15,8 persen. Bahkan terdapat 0,5 persen perempuan dan 0,1 persen lakilaki yang sudah melakukan hubungan seksual pertama kali pada usia 8 tahun. Riskesdas (2010) juga menyebutkan bahwa 4,8 persen remaja usia 10-14 tahun dan 41,9 persen pada usia 15-19 tahun sudah menikah. Sementara dari hasil SDKI (2012) dijelaskan ada 12,8 persen remaja usia 15 - 19 tahun sudah menikah. Ini berarti, remaja melakukan hubungan seks dan mengalami kehamilan dalam usia yang sangat muda. Kehamilan remaja meningkatkan risiko kesehatan dan kematian pada ibu dan anak. Kasus aborsi di kalangan remaja juga sangat mengkhawatirkan. Dari 2,3 juta kasus aborsi per tahun di Indonesia, 30 persen dilakukan oleh remaja. Kehamilan di usia muda dan aborsi berpengaruh buruk terhadap kesehatan reproduksi remaja tersebut pada saat ini maupun nanti.

Di samping itu, meningkatnya umur kawin pertama dan bertambah besarnya proporsi remaja yang belum kawin yang disebabkan oleh makin banyaknya remaja, baik laki-laki maupun perempuan meneruskan pendidikan ke jenjang yang lebih tinggi dan semakin banyaknya remaja yang berpartisipasi dalam pasar kerja. Panjangnya waktu dalam status lajang maupun kesempatan mempunyai penghasilan, mempengaruhi remaja untuk berperilaku berisiko TRIAD, seperti menjalin hubungan seksual pranikah yang dapat mengakibatkan KTD, aborsi, dan IMS termasuk HIV/AIDS, serta penyalahgunaan NAPZA.

Agar remaja mampu menghadapi berbagai tantangan, termasuk risiko TRIAD KRR, maka remaja perlu dibantu dan difasilitasi dengan berbagai keterampilan, di antaranya keterampilan hidup (life skills) dalam bidang kesehatan reproduksi yang mencakup kemampuan untuk tumbuh dan berkembang secara fisik, mental, emosional, dan spiritual. Keterampilan hidup sebaiknya diajarkan sedini mungkin agar risiko TRIAD KRR yang dihadapi remaja seperti saat ini akan dapat diatasi dengan lebih efektif (Muadz, dkk., 2008). Keterampilan hidup dalam bidang $\mathrm{KRR}$, antara lain adalah siswa (remaja) yang memiliki: 
keterampilan memecahkan masalah dan mengambil keputusan, (2) keterampilan berpikir (berpikir positif), (3) keterampilan komunikasi interpersonal, (4) keterampilan menjaga kesehatan fisik, (5) keterampilan bersikap tegas, (6) keterampilan mempercayai dan menghargai diri sendiri, dan (7) keterampilan menghadapi stres. Untuk itu perlu dikembangkan modul berbasis masalah untuk mendidik dan melatih keterampilan hidup (life skills) dan sikap reproduksi sehat siswa SMP (remaja) sebagai upaya untuk mewujudkan tegar remaja, yaitu remaja yang berperilaku sehat, terhindar dari risiko TRIAD KRR, dan menjadi sumber informasi TRIAD KRR yang bertanggung jawab bagi teman sebayanya. Berdasarkan latar belakang masalah tersebut, pengembangan dan penyusunan modul Kesehatan Reproduksi Remaja Berbasis Masalah (KRRBM) penting untuk segera dilakukan. Modul KRRBM merupakan modul yang dikemas berdasarkan masalah kesehatan reproduksi remaja yang ada di sekitar siswa sebagai konteks untuk memahami materi (content) yang dipelajari. Dengan difasilitasi modul KRRBM, siswa dilatih dan diberikan bekal pengetahuan dan keterampilan pemecahan masalah, dan mengambil keputusan terkait kesehatan reproduksi. Peningkatan pengetahuan akan mengubah sikap (Naidoo dan Wills, 2000). Perubahan sikap yang dihasilkan melalui proses pendidikan akan berlangsung relatif lama.

Adapun tujuan penelitian adalah melakukan analisis kebutuhan untuk memperoleh data dalam penyusunan modul KRRBM untuk mendidik dan melatih keterampilan hidup (life skills) dan membelajarkan sikap reproduksi sehat pada siswa, sehingga mereka dapat tumbuh dan berkembang menjadi tegar remaja.

\section{METODE PENELITIAN RANCANGAN PENELITIAN}

Untuk mencapai tujuan penelitian, dilakukan penelitian pengembangan. Model pengembangan modul KRR berbasis masalah yang digunakan mengacu pada model pengembangan Dick dan Carey (1990). Tahapan pengembangan terdiri atas lima tahap yaitu: 1) tahap penetapan materi pelajaran, 2) tahap analisis kebutuhan, 3) tahap pengembangan modul KRR berbasis masalah, 4) tahap penyusunan modul, dan 5) tahap review/uji coba. Dengan mengacu pada model pengembangan yang digunakan, maka penelitian tahap pertama dilakukan: (a) penetapan materi pelajaran, (b) analisis kebutuhan, (c) pengembangan modul KRR berbasis masalah, dan (d) penyusunan prototipe modul KRRBM.

\section{POPULASI DAN SAMPEL}

Populasi penelitian ini adalah Kepala Sekolah, guru IPA, dan siswa SMP Negeri dan Swasta yang ada di Kota Singaraja - Bali. Jumlah sekolah yang dilibatkan adalah 10 sekolah, lima SMPN Negeri dan lima SMPN Swasta. Penentuan SMP sebagai sampel penelitian dilakukan dengan teknik purposif random sampling.

\section{TEHNIK PENGUMPULAN DATA}

Pengumpulan data dilakukan dengan cara sebagai berikut.

1) Wawancara mendalam dengan Kepala Sekolah dan guru IPA (Biologi), dan masing-masing enam siswa dari lima SMPN (SMPN 1, 
SMPN 2, SMPN 3, SMPN 4, dan SMPN 6), dan lima SMP Swasta (SMP Lab Undiksha, SMP Bhaktiyasa, SMP Mutiara, SMP Santo Paulus, dan SMP Saraswati) yang ada di kota Singaraja. Wawancara mendalam maksudnya adalah peneliti mengajukan pertanyaan sebagai pembuka, dan kemudian menggali sebanyakbanyaknya jawaban dari responden. Wawancara ini dilakukan untuk mendapatkan data tentang pelaksanaan PKRR di sekolah masing-masing.

2) Angket. Angket diberikan kepada siswa dan guru IPA yang bertujuan untuk mengetahui profil siswa dan pendapat mereka tentang pendidikan kesehatan reproduksi remaja. Angket ini diisi sendiri oleh responden (self administered).

3) Diskusi kelompok terfokus (Focus group discussion). Peneliti menggali informasi dari guru-guru pengajar mata pelajaran IPA (Biologi) sekaligus dalam kelompok. Tujuan FGD adalah memperoleh informasi yang lebih mendalam dari guru tentang PKRR yang sudah dilakukan dan rancangan PKRR yang akan dilakukan.

\section{ANALISIS DATA}

Data kualitatif dan kuantitatif yang diperoleh dianalisis secara deskriptif dengan cara menyusun data secara sistematis, mengorganisasi data ke dalam kategori, melakukan sintesa, menyusun dalam pola tertentu, dan membuat kesimpulan.

\section{HASIL DAN PEMBAHASAN \\ HASIL PENELITIAN}

Dari wawancara dengan kepala sekolah dan guru, pengisian angket oleh guru dan siswa, serta FGD dengan guru-guru IPA dari sekolah, diperoleh data sebagai berikut.

1) Beberapa materi tentang $K R R$ sudah diberikan pada mata pelajaran IPA. Materi KRR tersebut meliputi perkembangan fisik remaja, anatomi fisiologi dan penyakit pada sistem reproduksi manusia, menjaga kebersihan organ-organ reproduksi, dan NAPZA.

2) Materi KRR juga diberikan pada kegiatan ekstrakurikuler Kelompok Siswa Peduli AIDS dan Narkoba (KS-PAN) dan PMR, dan diberikan pada saat kegiatan masa orientasi siswa (MOS) baru.

3) Strategi pembelajaran yang digunakan dalam membelajarkan materi KRR belum melatih keterampilan hidup terkait KRR, dan belum membelajarkan sikap terkait KRR.

4) Kendala yang dihadapi sekolah dalam PKRR adalah kedalaman dan sistematika materi KRR, strategi pembelajaran yang sesuai untuk PKRR di SMP, buku sumber, waktu, dan biaya.

5) Siswa SMP memerlukan informasi tentang KRR dan setuju diberikan PKRR di sekolah.

6) Guru setuju PKRR sebaiknya dilakukan secara terintegrasi pada semua mata pelajaran yang relevan dan dirancang secara sistematis di bawah kordinasi UKS. Guru yang memberikan PKRR adalah guru 
yang sudah dibina dan dilatih pada bidang PKRR.

7) Sekolah sangat setuju dikembangkan dan disusunnya modul KRRBM untuk membelajarkan siswa tentang KRR.

\section{PEMBAHASAN}

Agar siswa dapat terhindar dari masalah kesehatan reproduksi, maka remaja hendaknya diberikan pemahaman dan berbagai keterampilan, di antaranya keterampilan hidup (life skills) dalam bidang kesehatan reproduksi yang mencakup kemampuan untuk tumbuh dan berkembang secara fisik, mental, emosional, dan spiritual. Keterampilan hidup sebaiknya diajarkan sedini mungkin agar risiko TRIAD KRR yang dihadapi remaja seperti saat ini akan dapat diatasi dengan lebih efektif (Muadz, dkk., 2008).

Kesehatan siswa, termasuk kesehatan reproduksi mutlak diperlukan. Sumber informasi siswa tentang KRR yang paling banyak didapatkan dari media, kemudian dari guru (Suharyo, 2009). Pendidikan kesehatan reproduksi remaja di sekolah merupakan salah satu upaya untk meningkatkan derajat kesehatan siswa. $\mathrm{Hal}$ ini sesuai dengan Undang-undang RI Nomor 20 Tahun 2003 tentang Sistem Pendidikan Nasional, yang menyatakan bahwa untuk mencapai tujuan nasional pendidikan diperlukan sumber daya manusia yang berkualitas yang antara lain diwujudkan dengan menciptakan lingkungan pendidikan sehat bagi peserta didik (Catio, 2009). Pendidikan nasional bertujuan untuk berkembangnya potensi peserta didik agar menjadi manusia yang beriman dan bertakwa kepada Tuhan Yang
Maha Esa, berakhlak mulia, sehat, berilmu, cakap, kreatif, mandiri, dan menjadi warga negara yang demokratis serta bertanggung jawab (pasal 3 UU RI Nomor 20 Tahun 2003).

Banyak penelitian menunjukkan bahwa pengetahuan remaja tentang seksualitas dan kesehatan reproduksi masih rendah (Muzzayanah, 2008; Noviasari, dkk.,2008; Catio, 2009; Prameswara, 2009, dan Zahra, 2010). Rendahnya pengetahuan remaja tentang KRR merupakan salah satu risiko bagi remaja untuk mengalami masalah KRR. Beberapa materi KRR yang seharusnya diketahui oleh siswa (remaja) sudah ada pada mata pelajaran IPA (Biologi). Materi KRR diberikan pada mata pelajaran IPA (Biologi) di kelas VIII dan IX. Materi KRR juga diberikan pada mata pelajaran BK, dan kegiatan ekstrakurikuler KS-PAN dan PMR, tetapi pemberian materi yang terpisah-pisah, kurang sistematis, dan tidak ada koordinasi di antara mata pelajaran dapat menimbulkan kebingungan pada siswa. Kondisi seperti ini akan mendorong siswa untuk mencari informasi pada sumber lain yang belum tentu benar (Muzzayanah, 2008).

Terdapatnya materi KRR pada mata pelajaran IPA maupun BK menunjukkan bahwa PKRR dapat dilakukan secara terintegrasi pada mata pelajaran tersebut. Integrasi tersebut harus dilakukan dengan sistematis dan strategi pembelajaran yang tepat. Penelitian menunjukkan bahwa layanan informasi KRR melalui BK cukup efektif dalam meningkatkan pengetahuan KRR siswa (Wulandari, dkk., 2012).

Strategi pembelajaran yang digunakan guru selama ini dalam 
membelajarkan materi KRR antara lain pembelajaran langsung, kooperatif STAD, problem solving, diskusi dan informasi. Materi KRR dan strategi pembelajaran yang dipilih harus dirancang secara khusus sesuai dengan kebutuhan remaja (siswa) dan memperhatikan semua aspek perkembangan dari peserta didik (siswa). Pada pembelajaran di SMP, seorang guru harus dapat memilih pendekatan dan berbagai strategi pembelajaran yang tepat, sehingga dapat menimbulkan kegairahan, kesenangan, kreativitas pada siswa. Guru berperan sebagai "orang tua" siswa di sekolah. Pembelajaran di SMP diharapkan dapat memfasilitasi dan memotivasi proses belajar siswa dengan memberi kesempatan yang sering kepada siswa untuk berinteraksi dengan teman sebaya dalam suasana tidak kompetitif, dan tidak ditentukan oleh kemampuan siswa, Sebagaimana yang dikemukakan oleh Nur (2004), Yusuf (2004), Muijs dan Reynolds (2008), dan Sanjaya (2009) bahwa kondisi pembelajaran yang kondusif dan harmonis dapat menumbuhkan sikap saling menghargai, saling mempercayai, dan bertanggung jawab. Di samping itu, strategi pembelajaran yang dipilih juga memberi kesempatan yang sering bagi siswa untuk melatih membuat keputusan dan pilihan-pilihan oleh mereka sendiri. Interaksi yang lebih sering dilakukan dengan guru dan teman-teman sebaya (siswa lainnya) dalam kelompok yang lebih kecil, sehingga interaksi yang akrab dapat berkembang (Nur, 2004). Interaksi antara teman sebaya akan mempengaruhi sikap siswa (Iryanti, 2004 dan Teguh, dkk., 2013). Adanya interaksi antara siswa, dan antara siswa dan guru dapat meningkatkan hasil belajar siswa (Dewi, dkk., 2013 dan Ostroff, 2013), dan melatih siswa dalam berkomunikasi.

Ditinjau dari teori perkembangan kognitif dari Piaget, masa remaja (siswa SMP) sudah mencapai tahap operasional formal (operasi = kegiatankegiatan mental tentang berbagai gagasan). Remaja secara mental sudah dapat berpikir logis tentang berbagai gagasan yang abstrak, serta sistematis dan ilmiah dalam memecahkan masalah (Yusuf, 2004). Perkembangan kognitif siswa SMP memungkinkan untuk dibelajarkan dengan strategi pembelajaran berbasis masalah. Masalah yang dikaji dalam PKRR merupakan masalah real yang terjadi di lingkungan siswa atau yang dialami oleh siswa. Karena keterbatasan bahan ajar KRR di SMP, maka untuk memfasilitasi PKRR yang sesuai dengan kebutuhan siswa dan tujuan pembrlaaran IPA, maka perlu dikembangkan modul KRRBM berbasis masalah.

PKRR secara terintegrasi pada mata pelajaran IPA dapat dilakukan dengan strategi pembelajaran berbasis masalah. Pada kegiatan pembelajaran tersebut, siswa dilatih memecahkan masalah kesehatan reproduksi secara ilmiah. Pembelajaran berbasis masalah pada PKRR menempatkan siswa pada masalah tersebut, sehingga dapat melatih siswa untuk memahami orang lain. Pembelajaran yang membelajarkan siswa untuk dapat memahami orang lain merupakan pembelajaran sikap (Sanjaya, 2009). Dalam Krishnan, dkk. (2011) dan Eggen dan Kauchak (2012) dikemukakan bahwa pembelajaran berbasis masalah manggunakan 
masalah sebagai fokus untuk mengembangkan keterampilan pemecahan masalah, bekerja sama (kolaborasi), berkomunikasi, dan memahami materi yang dipelajari. Ini berarti bahawa pembelajaran dengan pemecahan masalah KRR tersebut akan meningkatkan hasil belajar sikap, sehingga sikap reproduksi siswa menjadi lebih positif.

Penelitian yang dilakukan oleh Adnyana, dkk. (2003) ditemukan bahwa pembelajaran berbasis masalah dapat memberikan bekal kecakapan hidup seperti kecakapan berpikir kritis, kecakapan akademik, dan kecakapan sosial peseta didik. Pembelajaran berbasis masalah menigkatkan keterampilan berpikir kritis dikemukakan oleh Afcariano (2008), Darmawan (2010), Krishnan et al. (2011), dan Astika dkk. (2013). Dengan meningkatnya keterampilan berpikir pada siswa akan meningkatkan pula keterampilan hidup dalam bidang KRR.

Keterampilan atau kecakapan yang dapat dilatihkan melalui pembelajaran berbasis masalah sangat penting dalam PKRR agar siswa memiliki keterampilan hidup dalam bidang KRR. Untuk memfasilitasi strategi pembelajaran berbasis masalah pada PKRR maka disusun modul KRRBM.

\section{PENUTUP}

1) Kepala sekolah dan guru IPA sangat setuju memberikan PKRR kepada siswa SMP, karena siswa SMP memerlukan informasi yang benar tentang KRR agar bisa terhindar dari masalah KRR

2) Sebagian materi tentang KRR sudah diberikan pada mata pelajaran IPA (biologi) dan melalui kegiatan ekstrakurikuler KS-PAN, PMR, dan pada saat MOS.

3) Strategi pembelajaran yang digunakan dalam membelajarkan materi KRR belum melatih keterampilan hidup siswa dalam bidang KRR dan belum membelajarkan siswa tentang sikap reproduksi sehat.

4) PKRR sebaiknya diberikan secara terintegrasi pada mata pelajaran yang relevan, dirancang secara khusus sesuai dengan kebutuhan siswa SMP, dan diberikan oleh guru yang sudah terlatih.

5) Modul KRRBM yang disusun diharapkan dapat memfasilitasi pembelajaran pada PKRR untuk melatih keterampilan hidup siswa dalam bidang KRR dan membelajarkan sikap reproduksi sehat pada siswa.

\section{DAFTAR PUSTAKA}

Adnyana, B. P., D.M. Citrawathi, I N. Sumardika, I N. Kariasa. 2003. Pengembangan Model Pembelajaran Sains (Biologi) pada Pendidikan Dasar dan Menengah dengan Menerapkan Pembelajaran Berbasis Masalah untuk Mencapai Kompetensi dan Pembekalan Kecakapan Hidup (Life Skills) (Laporan Penelitian). Singaraja: IKIP Negeri

Afcariano, M. 2008. Pembelajaran Berbasis Masalah untuk Meningkatkan Kemampuan Berpikir Siswa pada mata Pelajaran Biologi. Jurnal Pendidikan Inovatif. 3(2): 65-68 
Astika, I K. U., I K. Suma, I W. Suastra. 2013. Pengaruh Pembelajaran Berbasis Masalah terhadap Sikap IImiah dan Keterampilan Berpikir Kritis. e-Journal Program Pascasarjana Universitas Pendidikan Ganesha Program Studi IPA. Vol. 3: 1-10

Catio, M. 2009. Peran Pendidikan dalam Mengatasi Masalah Kesehatan Remaja. Aviable from: http://www.idai.or.id/remaja/artikel. asp?q=2009113012438 . Accesed 24 Nopember 2010

Darmawan. 2010. Penggunaan Pembelajaran Berbasis Masalah dalam Meningkatkan Kemampuan Berpikir Kritis Siswa pada Pembelajaran IPS di MI Darrussaadah Pandeglang. Jurnal Penelitian Pendidikan UPI 11(2): 106-117.

Dewi A.N., S. Dwiastuti, dan A.A. Prayitno. 2013. Pengaruh Penggunaan Model Active Knowledge Sharing terhadap Hasil Belajar ditinjau dari Minat Belajar Siswa SMAN 2 Karanganyar. Makalah Hasil Penelitian. Disampaikan dalam Seminar Nasional IX Pendidikan Biologi FKIP UNS.

Dianawati, A. 2003. Pendidikan Seks untuk Remaja. Jakarta: Kawan Pustaka

Dick, W. dan L. Carey. 1990. The Systematic Design of Instruction, $\left(3^{\text {rd }}\right.$ ed). London: Scott, Foresman and Company.

Duarsa D.P. 2009. Persepsi Remaja tentang Hubungan Seks Pranikah di Kota Denpasar: Perspektif Kajian Budaya. Disertasi. Denpasar: Universitas Udayana

Eggen, P. dan D. Kauchak. 2012. Strategi dan Model Pembelajaran. Mengajarkan Konten dan Keterampilan Berpikir. Edisi ke 6. (Penerjemah: Satrio Wahono). Jakarta: Indeks

Iryanti. 2004. Pengaruh Pendidikan Kesehatan Reproduksi melalui Metode Pendidikan Sebaya terhadap Pengetahuan dan Sikap Remaja dalam Pencegahan Kehamilan tan Diinginkan (KTD) di SMKN 15 Kotamadya Bandung. Jurnal Kesehatan Kartika Stikes A. Yani. 30-39.

Kisara. 2008. Bangkitkan Eksistensi Remaja demi Hak-hak Remaja. PKBi - Bali

Krishnan, S., R. Gabb, dan C. Vale. Learning Cultures of ProblemBased-Learning Teams. Australian Journal of Engineering Education. 17(2): 67-77

Muadz, M.M., F. Siti , A.S.Endang, dan M. Laurike. 2008. Keterampilan Hidup (Life Skills) dalam Program Kesehatan Remaja. Jakarta: BKKBN Direktorat Remaja dan Perlindungan Hak-Hak Reproduksi

Muijs, D. dan D. Reynold. 2008. Effective Teaching Teori dan Aplikasi. (Helly Prajitno Soetjipto dan Sri Mulyantini Soetjipto, Pentj). Yogyakarta: Pustaka Pelajar.

Muzayyanah, S.N., 2008. Pendidikan Kesehatan Reproduksi Remaja: Bagaimana Menyikapinya? 
Aviable

from: http://halalsehat.com/index.php/An ak-sehat/ . Accesed 4 September 2010

Naidoo, J. Dan J. Wills. 2000. Health Promotion. Foundation for Practice. $2^{\text {nd }}$ ed. China: Bailliere Tindall

Noviasari, E., N. S. Kiki, N.M.Irm. 2008. Mata Pelajaran Reproduksi Remaja dalam Kurikulum SMP untuk Menghindari Remaja dari Tindak Aborsi akibat Free Sex (Laporan Penelitian). Universitas Negeri Malang.

Nur, M. 2004. Perkembangan Selama Anak-anak dan Remaja: Malang: Universitas Negeri Malang

Ostroff, W.L. 2013. Memahami Cara Anak-anak Belajar: Membawa IImu Perkembangan Anak ke dalam Kelas. (B. Sendra Tanuwijaya, Pentj). Jakarta : PT Indeks

Pramesemara. 2009. Perlunya Pendidikan Seks yang Benar untuk Remaja. Aviable from: http://kisarayouthclinic.org.

Accesed 23 Oktober 2011

Riset Kesehatan Dasar (Riskesdas). 2010. Badan Penelitian dan Pengembangan Kesehatan Kementerian Kesehatan Republik Indonesia.

Sanjaya, W. 2009. Strategi Pembelajaran Bertorientasi Standar Proses Pendidikan. Cetakan ke-6. Jakarta: Prenada Media Group

Suharyo. 2009. Faktor-faktor Predisposisi Praktek Pendidikan
Kesehatan Reproduksi Remaja. Jurnal Kesehatan Masyarakat Universitas Negeri Semarang 5(1): 1 - 10

Survei Demografi dan Kesehatan Indonesia (SDKI). 2012. Kesehatan Remaja. Badan Pusat Statistik Badan Kependudukan dan Keluarga Berencana Nasional Kementerian Kesehatan.

Teguh, A., T. Istiarti, Widagdo, L. 2013. Hubungan Pengetahuan, Sikap terhadap Kesehatan Reproduksi Remaja dengan Praktik Seksual Pranikah pada Mahasiswi Kebidanan di Politeknik Kesehatan Depkes Semarang. Jurnal Kesehatan Masyarakat. 2(2). Available at: http://ejournals1.undip.ac.id/index. php/jkm . Accessed 10 Maret 2013

Wulandari, V.F., Herman N., Nurfarhanah. 2012. Pemahaman Siswa Mengenai Kesehatan Reproduksi Remaja melalui Layanan Informasi. Jurnal IImiah Konseling, FIP UNP.1(1):1-9

Yusuf, L.N.S. 2004. Psikologi Perkembangan Anak dan Remaja. Bandung: Rosdakarya.

Zahra, A. A. 2010. Genting Pendidikan Kesehatan Reproduksi. Aviable from:

http://mylearningissue.wordpress.c om/2010/02/21. Accesed 23 Mei 2011.

Jurnal IImu Sosial dan Humaniora | 483 